\title{
The Grid-connected Inverter of Simulation on Direct-drive Wind Power System Based on MATLAB
}

\author{
WANG Xiaoming \\ School of Electrical and \\ Information Engineering, \\ Lanzhou University of Technology \\ Lanzhou,Gansu,China,730050 \\ majing111111@sina.com
}

\author{
LIU Wanci \\ School of Electrical and \\ Information Engineering, \\ Lanzhou University of Technology \\ Lanzhou,Gansu,China,730050 \\ 525828330@qq.com
}

\author{
XIAO Wenjuan \\ School of Electrical and \\ Information Engineering, \\ Northwest University of \\ Nationalities \\ Lanzhou,Gansu,China,730050 \\ 119263216@qq.com
}

\begin{abstract}
Based on working Principle of the direct-drive wind power system's grid-connected inverter was research, the mathematical model for inverter in Three-phase rotating coordinate was established and analyzed. A double-loop control strategy that based on feed forward decoupling were introduced, Meanwhile, combining the implementation effective control of the AC-side output current by the Space Vector Pulse Width Modulation method (SVPWM), it could generate sine wave current that had the same frequency and the same phase with network voltage. To a great degree, reduced harmonic pollution in power system, moreover, improved the Grid-connected wind power system's efficiency and reliability.
\end{abstract}

Keywords-Grid-connected inverter; wind power system; direct-drive; SVPWM; Simulink/Matlab

\section{INTRODUCTION}

Today, with the deepening world energy crisis and the rising the public' requirements to improve the ecological environment, wind energy, as a kind of clean and renewable energy, was paid much attention to by governments all around the world[1]. Now, the advantages of direct-drive wind power system in the grid-connected system favored by the researchers [2]. The paper proposed the problem of the direct-drive permanent-magnet synchronous grid-connected wind power system, studied on control strategy of the line side inverter. This subject adopted that the instantaneous output current control technology and as the network voltage synchronization signal to be the output current tracking reference. So, inverter of current could quickly track the network voltage signal and realize unity power factor to grid connect and decoupling control of active and reactive power. Meanwhile, the system got stable dc-voltage. The matlab/simulink was applied for the system modeling and simulation analysis.

\section{WORKING PRINCIPLE OF THE GRID CONNECTED INVERTER}

The topological structure of three-phase voltage-type inverter was shown in figure 1.

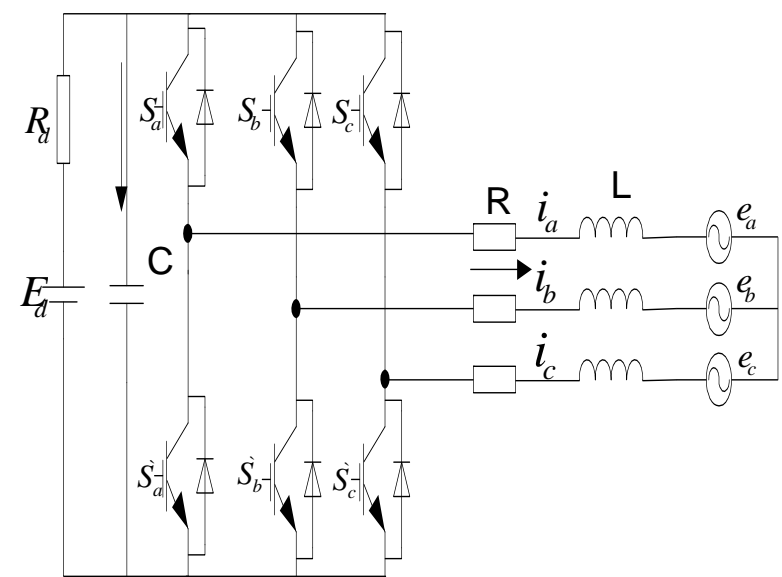

Fig.1 Topological structure of three-phase voltage type inverter

The paper presents a general establishment mathematical model of three-phase voltage source rectifier (VSR) and makes some assumptions, for example [3]:

(1) The gird electromotive force $\left(e_{a}, e_{b}, e_{c}\right)$ was as stable three-phase pure sine wave electromotive force.

(2) The grid filter inductance L was linear and did not consider saturation.

(3) Resistance $\mathrm{R}$ represents power switching loss; this mean that an equivalent expressing method of the actual power switch tube was the ideal switch and resistance $\mathrm{R}$ in series.

The three-phase VSR topology structure could get the dq coordinates mathematical model, namely,

$$
\left\{\begin{array}{l}
e_{d}=L \frac{d i_{d}}{d t}+R i_{d}+\omega L i_{q}+u_{d} \\
e_{q}=L \frac{d i_{q}}{d t}+R i_{q}-\omega L i_{q}+u_{q}
\end{array}\right\}
$$

In figure (1), $e_{d}$ and $e_{q}$ were the dq axis component of the grid electromotive force vector; $u_{d}$ and $u_{q}$ were the dq axis component of the three-phase VSR voltage vector in AC-side. $i_{d}, i_{q}$ were the dq axis component of the threephase VSR current vector in AC-side, $\mathrm{L}$ was filter 
inductance in AC-side, $\mathrm{C}$ was capacitance in DC-side, $\mathrm{R}$ was the equivalent resistance.

\section{THE CONTROL METHOD OF THE SYSTEM}

\section{A. feed forward decoupling control}

After coordinate transformed, fundamental sine variables in three-phase symmetrical static coordinates transformed into Dc in a synchronous rotating frame, but it could be seen this was a strong coupling system from formula(1), the dq axis current changed influence each other. In order to realize the control of the current, the control strategy of the grid voltage synthetic vector orientation was given in study. The d-axis in a synchronous rotating dq coordinate oriented vector $E$ in the grid voltage synthetic vector, and the q-axis led the d-axis $90^{\circ}$. When the current regulator chose PI regulator, a control strategy based on feed forward decouple and feed forward compensation were introduced, the governing equations of $u_{d}, u_{q}$ was shown in figure (2).

$$
\left\{\begin{array}{l}
v_{d}^{*}=-\left(k_{p}+\frac{k_{i}}{S}\right)\left(i_{d}^{*}-i_{d}\right)-\omega L i_{q}+e_{d} \\
v_{q}^{*}=-\left(k_{p}+\frac{k_{i}}{S}\right)\left(i_{q}^{*}-i_{q}\right)+\omega L i_{d}+e_{q}
\end{array}\right\}
$$

In which $k_{p}, k_{i}$ represented the proportion parameter of Control Loop and integral parameter, $u_{d}$ and $u_{q}$ commanded AC voltage on inverter side in rotary two-phase coordinates, $i_{d}^{*}$ and $i_{q}^{*}$ commanded inverter current on ACside. The current inner loop control strategy joining the voltage outer loop of PI control form a double closed loop control system. The role of current inner loop was control current according to the current command of voltage outer ring output, for example, realizing unity power factor to sine wave current control. The role of voltage outer loop was mainly voltage control in DC-side. Control block diagram was shown in Figure 2.

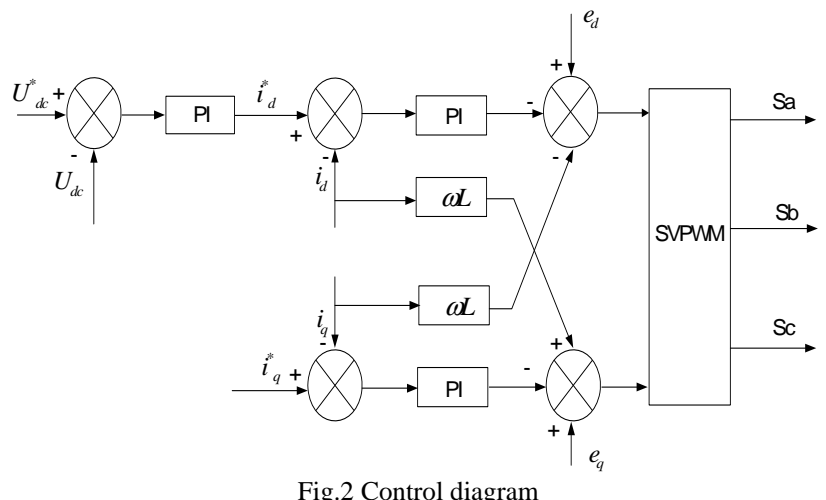

B. Space Vector Pulse Width Modulation(SVPWM)Algorithm

The control strategy of SVPWM was divided into three parts: interval distribution of three-phase voltage, the best sequence selection of vector synthesis and control algorithm [4]. The interval of voltage distribution directly influence specific control algorithm, and the sequence selection of vector synthesis related to switching loss and harmonic components [5].

1) Judge command voltage $v_{\text {ref }}$ in sector

$v^{*}{ }_{d}$ and $v_{q}^{*}$ changed into $v_{\alpha}$ and $v_{\beta}$ by coordinate transformation, both synthetic voltage vectors in sector was given by the following simple algorithm calculation.

Making

$$
\left\{\begin{array}{l}
u_{1}=u_{\beta} \\
u_{2}=\sqrt{3} u_{\alpha}-u_{\beta} \\
u_{3}=-\sqrt{3} u_{\alpha}-u_{\beta}
\end{array}\right\}
$$

$A=\left\{\begin{array}{l}1, u_{1}>0 \\ 0, u_{1} \leq 0\end{array}, B=\left\{\begin{array}{l}1, u_{2}>0 \\ 0, u_{2} \leq 0\end{array}, C=\left\{\begin{array}{l}1, u_{3}>0 \\ 0, u_{3} \leq 0\end{array}\right.\right.\right.$

Namely, the reference voltage vector in sector determined by the relationship between $u_{\beta}$, $\sqrt{3} u_{\alpha}-u_{\beta},-\sqrt{3} u_{\alpha}-u_{\beta}$ and 0 . Between A, B and C could be seen eight kinds of combination, in fact $\mathrm{A}, \mathrm{B}$ and $\mathrm{C}$ would not at the same time for 1 or at the same time for 0 . So their combinations were six, they took on different values representing to different sectors and each corresponding values were unique. In order to distinguish six states, the paper assumed $N=4 * C+2 * B+A$, and it could calculate reference voltage vector of sector through the table 1 . The simulation model was shown in figure 3.

Table 1 Sector judgment of reference voltage

\begin{tabular}{|c|c|c|c|c|c|c|}
\hline $\mathrm{N}$ & 3 & 1 & 5 & 4 & 6 & 2 \\
\hline sector & $\mathrm{I}$ & $\mathrm{II}$ & $\mathrm{III}$ & $\mathrm{IV}$ & $\mathrm{V}$ & $\mathrm{VI}$ \\
\hline
\end{tabular}

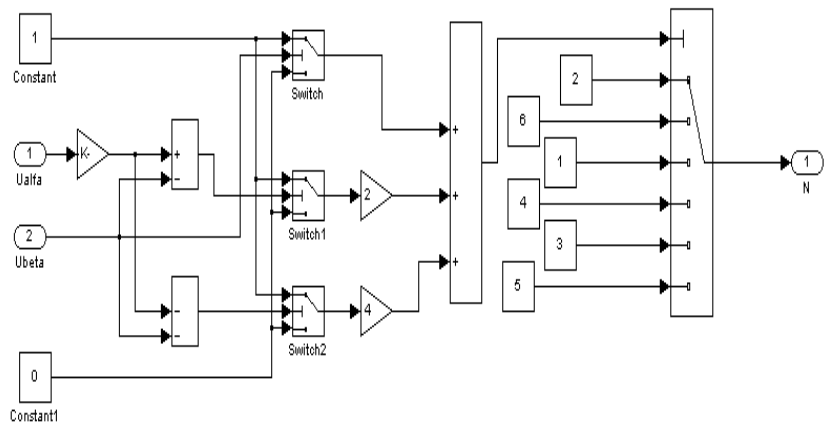

Fig3.Simulation model of sector judgment

2) Calculate action time of two adjacent switch voltage vectors

The $v_{\text {ref }}$ produced by interaction of the sector of two adjacent space vector. The vector of each sector occurring first was named principal vector, and $T_{x}$ represents it. Occurring vector later was named auxiliary vector, and $T_{y}$ represented it. The $\mathrm{X}, \mathrm{Y}, \mathrm{Z}$ represented action times, and 
it assumed $T_{x}+T_{y} \leq T_{x} 、 T_{y}$. T represented the carrier cycle. After analysis, the values of $\mathrm{X}, \mathrm{Y}, \mathrm{Z}$ may be calculated by the type (5). For different sectors, the action time of the basic vector values according the table 2 . The simulation model was shown in figure 4.

$$
\left\{\begin{array}{l}
X=\sqrt{3} u_{\beta} T / U_{d c} \\
Y=T\left(\sqrt{3} u_{\beta}+3 u_{\alpha}\right) / 2 U_{d c} \\
Z=T\left(\sqrt{3} u_{\beta}-3 u_{\alpha}\right) / 2 U_{d c}
\end{array}\right\}
$$

Table 2 Basic voltage vector's action time

\begin{tabular}{|c|c|c|c|c|c|c|}
\hline Sector & I & II & III & IV & V & VI \\
\hline$T_{x}$ & $-\mathrm{Z}$ & $\mathrm{Z}$ & $\mathrm{X}$ & $-\mathrm{Z}$ & $-\mathrm{Z}$ & $-\mathrm{Z}$ \\
\hline$T_{y}$ & $\mathrm{X}$ & $\mathrm{Y}$ & $-\mathrm{Y}$ & $\mathrm{Z}$ & $-\mathrm{Z}$ & $-\mathrm{X}$ \\
\hline
\end{tabular}

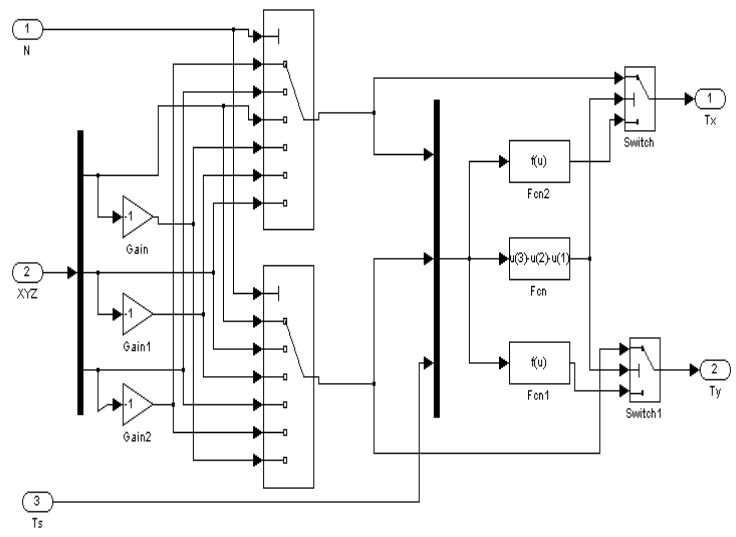

Fig.4 Simulation model of basic voltage vector's action time

3) The switch voltage vector action time synthesize three-phase PWM signal

According to switching rules and $T_{x}, T_{y}$, considering the sector is different, the switch action time $T_{\text {on1 }}, T_{\text {on2 } 2}, T_{\text {on3 }}$ may be calculated by the type (6).

Making

$$
\left\{\begin{array}{l}
T_{a}=\left(T-T_{x}-T_{y}\right) \\
T_{b}=T_{a}+T_{x} \\
T_{c}=T_{b}+T_{y}
\end{array}\right\}
$$

Switch action time and the simulation model were shown in table 3 and figure 5 .

Table 3 Switching voltage vector' section time

\begin{tabular}{|c|c|c|c|c|c|c|}
\hline Sector number & $\mathrm{I}$ & $\mathrm{II}$ & $\mathrm{III}$ & $\mathrm{IV}$ & $\mathrm{V}$ & $\mathrm{VI}$ \\
\hline$T_{\text {on } 1}$ & $T_{a}$ & $T_{b}$ & $T_{c}$ & $T_{c}$ & $T_{b}$ & $T_{a}$ \\
\hline$T_{\text {on } 2}$ & $T_{b}$ & $T_{a}$ & $T_{a}$ & $T_{b}$ & $T_{c}$ & $T_{c}$ \\
\hline
\end{tabular}

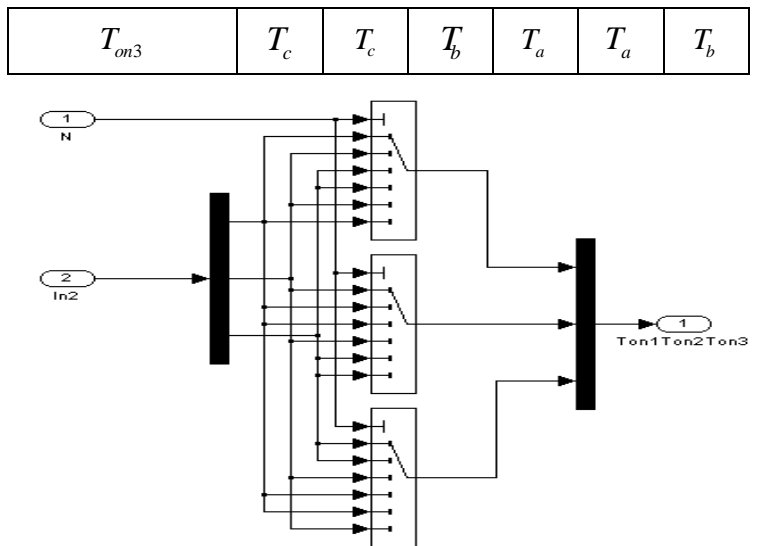

Fig.5 Simulation model of switching voltage vector's action time

\section{Simulation ANALYSES}

To test and verify the correctness of the design of control system, the paper set a simulation model in Matlab7.6 / Simulink with the following parameters: dc bus voltage instruction value was $1200 \mathrm{v}$; The rated power of grid inverter was $1.2 \mathrm{MW}$; the grid voltage peak is $690 \mathrm{v}$; switch frequency was $2 \mathrm{KHZ}$; capacitor in dc-side is $6.8 \mathrm{Mf}$, filtering inductance was $3.3 \mathrm{mH}$. The inverter bridge was used the general bridge provided by the system (IGBT+DIODE), the network power was used three-phase symmetrical voltage source to simulate; the angular frequency of grid voltage was calculated by Phase-locked loop (PLL) module [6]. For convenience observing, the design will be current and voltage the unitization, base voltage value is $690 \mathrm{v}$, the power was $1.2 \mathrm{MW}$.

In figure 6, it showed the system of A-phase voltage and current waveform in inverter status, and the current waveform reversed phase for the convenience of observation. The graph shows the current was a sine wave that is the same frequency and the reversing phase with the grid voltage. To achieve the good tracking performances; the grid power factor must be 1 .

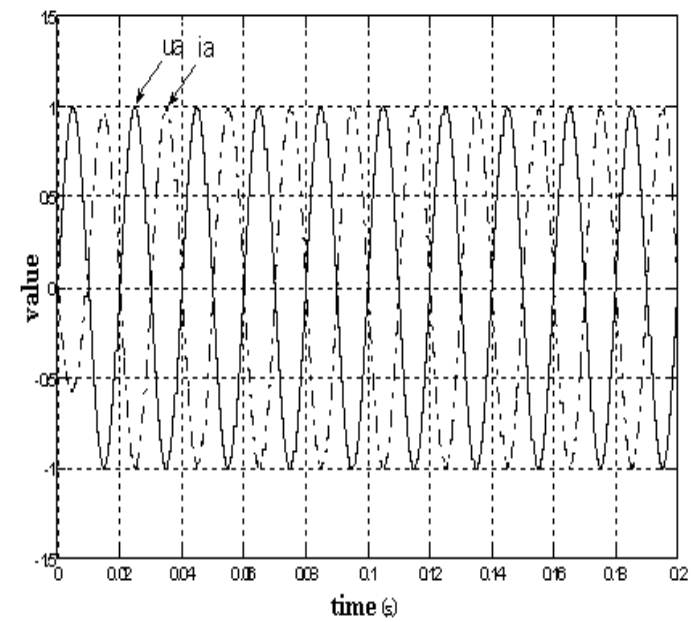

Fig.6 Simulation waveform of A phase voltage and current 
Another important function of the grid-connected inverter system was grid current harmonics meeting parallel in grid's standards. The result of the FFT analyses of grid current was shown in figure 7.

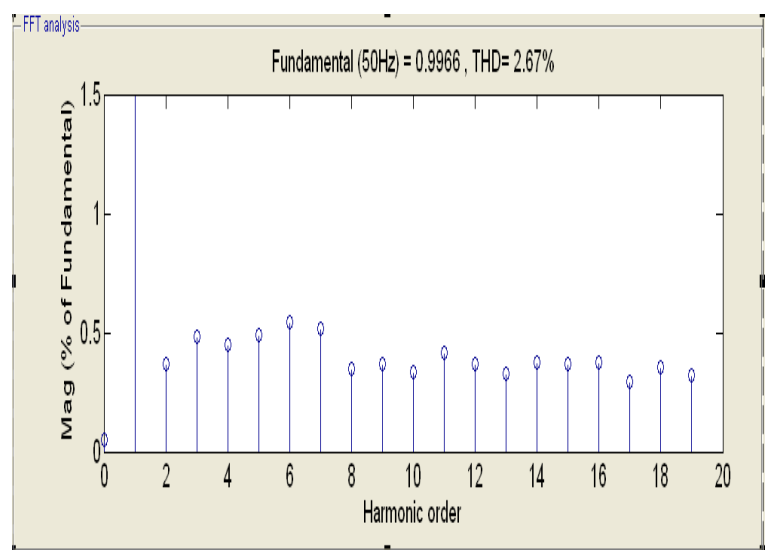

Fig.7 The FFT analysis of grid current (P.U)

From figure 7 , THD value is $2.67 \%$, and met the requirement of less than $\% 5$. Thus it could be seen that: the grid current harmonics of the system control output accorded with parallel in grid requirements.

In figure 8 , it showed the dc-side voltage value. Voltage value in dc side was stable at around $1200 \mathrm{v}$, and having a slight pulsating. We can see the outer voltage played a good control role.

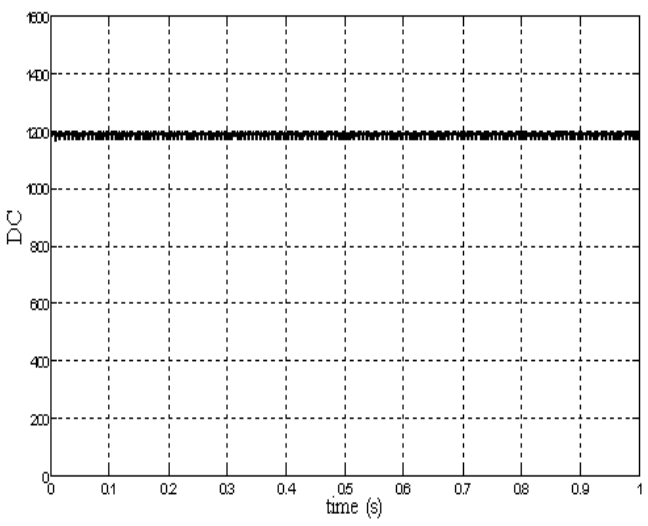

Fig.8 DC-side capacitance voltage

\section{CONCLUSION}

This paper analyzed the wind power grid inverter working principle, established the math model, and designed the double close-loop Control system, combined with SVPMW algorithm to realize the simulation of whole system [7]. Preparing for the study of the direct-drive wind power system, the result of simulation verified the correctness of the control system of the grid inverter in paper.

\section{REFERENCES}

[1] Yang XiuYuan, Liang GuiShu. The development of wind power and market prospect [J]. power system technology, 2003, 27(7): 78-79.
[2] Li Jianlin, Xu Honghua, Power and Electron Conversion technology in wind power [M]. Beijing: China Machine Press, 2008.

[3] ZHANG Chong, Zhang. PWM Rectifier and its Control Strategies[M]. Beijing: Machinery Industry Press.

[4] YANG Yong, RUAN Yi, SHEN Hanqing, ect. Grid-connected inverter for the wind power generation system[J]. Journal of Shanghai University (English), 2009, 13(1):51-56.

[5] Zhang HouSheng, Zhao YanLei. Wind power grid inverter of vector decoupling control study [J]. Electric drive, 2010, 40 (9): 28-32.

[6] Hong NaiGang. The simulation of power electronic and electric drive control system based on Matlab[M]. Beijing: Machinery Industry Press. 2006.

[7] Li JianLin, Gao Zhigang, Hu ShuJu, et al. Application of parallel back-to-back PWM converter on the direct-drive wind power system. Automation of Electric Power System, 2008, 32(5): 59-62. 